\title{
Adrenal insufficiency development during chemotherapy plus anti-programmed death receptor-1 monoclonal antibody (tislelizumab) therapy in patients with advanced gastric cancer: two case reports
}

\author{
Jin Ho Baek \\ Department of Oncology/Hematology, School of Medicine, Kyungpook National University, Kyungpook National University Chilgok \\ Hospital, Daegu, Korea
}

\begin{abstract}
Immune checkpoint inhibitor (ICI)-associated adrenal insufficiency is rare but may become a serious adverse event in patients treated with ICls. The present case report documents two cases of adrenal insufficiency developed during chemotherapy plus tislelizumab (百 泽安, Baize'an; BeiGene Ltd.) therapy in patients with advanced gastric cancer. Adrenal insufficiency developed after 6 and 13 cycles of treatment and was well controlled with hydrocortisone. The patients also developed hypothyroidism, which was managed with levothyroxine. Two patients showed a partial response, and one patient out of two achieved a near-complete response, sustaining over 11 months. Increased awareness of ICl-related adrenal insufficiency is crucial for early detection and prompt management of patients treated with ICls.
\end{abstract}

Keywords: Adverse events; Immune checkpoint inhibitors; Stomach neoplasms; Tislelizumab

\section{Introduction}

Gastric cancer is the fifth most common malignancy and the third leading cause of cancer-related mortality worldwide, even though rapid advances in treatment options have improved its prognosis [1]. Remarkable progress in tumor biology has led to the development of new therapeutics that target critical aspects of oncogenic pathways or the immune system. However, the prognosis of patients treated with standard treatment for advanced gastric cancer remains poor [2]. Programmed cell death protein 1 (PD-1) is a cell surface receptor that plays a significant role in downregulating the immune system and promoting self-tolerance by suppressing T-cell activity. Antibodies that block the interaction between PD-1 and programmed death-ligand 1 (PD-L1) allow the immune system to attack cancer cells. Anti-PD-1 and anti-PD-L1 antibodies have revolutionized the treatment of melanoma and non-small cell lung cancer (NSCLC) and are being evaluated in a broad range of other cancers, including gastric cancer.

Tislelizumab (百泽安, Baize’an; BeiGene Ltd., Beijing, China) is a humanized monoclonal antibody $(\mathrm{mAb})$ with high affinity and specificity for PD-1 that was engineered to minimize binding to $\mathrm{Fc}-\gamma$ receptor I ( $\mathrm{Fc} \gamma \mathrm{RI})$ on macrophages to greatly reduce anti-

Received: January 21, 2021 • Revised: March 8, 2021 • Accepted: March 9, 2021

Corresponding author: Jin Ho Baek, MD, PhD

Department of Oncology/Hematology, School of Medicine, Kyungpook National University, Kyungpook National University Chilgok Hospital, 807 Hoguk-ro, Buk-gu, Daegu 41404, Korea

Tel: +82-53-200-2674• Fax: +82-53-200-2029•E-mail: jhbaek@knu.ac.kr 
body-dependent phagocytosis, a potential mechanism of T-cell clearance and resistance to anti-PD-1 therapy [3].

The use of immune checkpoint inhibitors (ICIs) in cancer therapy is complicated by numerous mechanism-based toxicities, termed immune-related adverse events (irAEs), affecting dermatological, gastrointestinal, hepatic, endocrine, and other systems. Adrenal insufficiency is an irAE and may manifest as nonspecific symptoms. Delay in diagnosis and inadequate care can lead to serious complications. Although it is necessary to elucidate the detailed clinical features of this adverse event $(\mathrm{AE})$ for early detection, the clinical features of anti-PD-1 therapy-induced adrenal insufficiency remain poorly described.

Two cases of adrenal insufficiency are described in this study that developed during chemotherapy plus anti-PD-1 mAb (tislelizumab) therapy in patients with advanced gastric cancer in the clinical trial setting.

\section{Cases}

Ethical statements: This study was approved by the Institutional Review Board (IRB) of Kyungpook National University Chilgok Hospital (IRB No: 2019-05-021). Informed consent was obtained from the patients.

\section{Case 1}

A 58-year-old male was diagnosed with clinical T4N3M1, stage IV Her-2 negative gastric adenocarcinoma, with portal vein tumor thrombosis. He underwent palliative chemotherapy with capecitabine $\left(1,000 \mathrm{mg} / \mathrm{m}^{2}\right.$ twice daily, D1-D14), oxaliplatin (130 mg/ $\left.\mathrm{m}^{2}, \mathrm{D} 1\right)$, and tislelizumab $\left(200 \mathrm{mg} / \mathrm{m}^{2}, \mathrm{D} 1\right)$ at 3-week intervals. He received palonosetron $(0.25 \mathrm{mg})$ and dexamethasone (10 $\mathrm{mg}$ ), intravenously, before the infusion of oxaliplatin for the prevention of emesis. The initial treatment was well tolerated, and follow-up scans showed a partial response. He developed severe fatigue, and his serum sodium level was $109 \mathrm{mmol} / \mathrm{L}$ (range, 135$145 \mathrm{mmol} / \mathrm{L}$ ) after six cycles of treatment. Further investigations revealed the following: random urinary sodium, $64 \mathrm{mmol} / \mathrm{L}$; free T3, $0.39 \mathrm{pg} / \mathrm{mL}$ (range, $2.00-4.40 \mathrm{pg} / \mathrm{mL}$ ); free T4, $0.15 \mathrm{ng} / \mathrm{dL}$ (range, $0.89-1.8 \mathrm{ng} / \mathrm{dL}$ ); and thyroid-stimulating hormone (TSH) $136.50 \mathrm{mIU} / \mathrm{L}$ (range, $0.3-4.0 \mathrm{mIU} / \mathrm{L}$ ). The levels of antithyroglobulin antibody and antithyroid peroxidase were $70.60 \mathrm{U} /$ $\mathrm{mL}$ (range, $0-60 \mathrm{U} / \mathrm{mL}$ ) and $55.02 \mathrm{U} / \mathrm{mL}$ (range, $0-60 \mathrm{U} / \mathrm{mL}$ ), respectively. Thyroid ultrasonography showed atrophic changes in both lobes of the thyroid gland. The random serum adrenocorticotropic hormone (ACTH) level was $20.23 \mathrm{pg} / \mathrm{mL}$ (range, 0-60 $\mathrm{pg} / \mathrm{mL}$ ), and a rapid ACTH test was conducted. Before the admin- istration of $250 \mu \mathrm{g}$ of synthetic ACTH (cosyntropin), serum cortisol was $<0.5 \mu \mathrm{g} / \mathrm{dL}$ (range, 3.09-22.4 $\mu \mathrm{g} / \mathrm{dL}$ ). Postadministration values were 2.27 and $3.56 \mu \mathrm{g} / \mathrm{dL}$, at 30 and 60 minutes, respectively. Magnetic resonance imaging (MRI) of the brain showed no abnormalities in the pituitary gland (Table 1). The patient was diagnosed with hypothyroidism and adrenal insufficiency. The patient received levothyroxine $(0.15 \mathrm{mg})$ per day and $10 \mathrm{mg}$ of hydrocortisone twice daily. His serum sodium level improved to $138 \mathrm{mmol} /$ $\mathrm{L}$ after 1 week of treatment, and the patient reported improvement in fatigue. Follow-up investigations were conducted after 6 weeks of treatment and revealed the following: free $\mathrm{T} 3,3.03 \mathrm{pg} / \mathrm{mL}$; free $\mathrm{T} 4,1.41 \mathrm{ng} / \mathrm{dL}$; TSH, $13.10 \mathrm{mIU} / \mathrm{L}$; and random serum cortisol, $14.77 \mu \mathrm{g} / \mathrm{dL}$. Currently, the patient shows a near-complete response to treatment with capecitabine and tislelizumab. Hypothyroidism and adrenal insufficiency are well controlled with levothyroxine $(0.15 \mathrm{mg})$ per day and hydrocortisone twice daily $(10 \mathrm{mg}$ on awakening and $5 \mathrm{mg}$ in the early evening).

\section{Case 2}

A 59-year-old man was diagnosed with clinical T3N2M1, stage IV Her-2 negative gastric adenocarcinoma, with multiple metastases to the left paraaortic lymph node and liver. He underwent six cycles of palliative chemotherapy with capecitabine $\left(1,000 \mathrm{mg} / \mathrm{m}^{2}\right.$ twice daily, D1-D14), oxaliplatin $\left(130 \mathrm{mg} / \mathrm{m}^{2}, \mathrm{D} 1\right)$, and tislelizumab $\left(200 \mathrm{mg} / \mathrm{m}^{2}, \mathrm{D} 1\right)$ and seven cycles of capecitabine and tislelizumab from December 2019 to September 2020, resulting in a partial response. He received palonosetron $(0.25 \mathrm{mg})$ and dexamethasone (10 mg), intravenously, before the infusion of oxaliplatin for the prevention of emesis.

He developed severe weakness and mild dizziness after 13 cycles of treatment. Further investigations revealed the following: serum sodium, $123 \mathrm{mmol} / \mathrm{L}$; free T3, $4.44 \mathrm{pg} / \mathrm{mL}$; free T4, $1.05 \mathrm{ng} / \mathrm{dL}$; and TSH $8.28 \mathrm{mIU} / \mathrm{L}$. Additional tests for antithyroid antibodies and thyroid ultrasonography were not performed. Random serum cortisol was found to be $0.79 \mu \mathrm{g} / \mathrm{dL}$ and serum ACTH was 51.90 $\mathrm{pg} / \mathrm{mL}$ (Table 1). The patient was diagnosed with subclinical hypothyroidism and adrenal insufficiency. The patient was administered levothyroxine ( $0.05 \mathrm{mg}$ per day) and hydrocortisone (10 $\mathrm{mg}$ ) twice daily. His serum sodium level improved to $137 \mathrm{mmol} / \mathrm{L}$ after 1 week of treatment, and he reported improved condition and restarted treatment with capecitabine and tislelizumab. Follow-up investigations were conducted after 6 weeks of treatment and revealed the following: serum sodium, $135 \mathrm{mmol} / \mathrm{L}$; free $\mathrm{T} 3,4.62$ $\mathrm{pg} / \mathrm{mL}$; free T4, $1.46 \mathrm{ng} / \mathrm{dL}$; TSH, $3.67 \mathrm{mIU} / \mathrm{L}$; and random serum cortisol $9.15 \mu \mathrm{g} / \mathrm{dL}$. His disease progressed after 16 cycles of treatment. Currently, the patient receives second-line treatment with ramucirumab and paclitaxel. Hypothyroidism and adrenal in- 
Table 1. Summary of patient characteristics and clinical symptom, laboratory result, and imaging

\begin{tabular}{|c|c|c|c|c|c|c|}
\hline Case & $\begin{array}{l}\text { Age (yr) } \\
\text { /sex }\end{array}$ & Diagnosis & $\begin{array}{c}\text { Time of } \\
\text { symptom } \\
\text { onset }\end{array}$ & Presenting symptom & Laboratory result & Imaging result \\
\hline 1 & $58 / \mathrm{M}$ & $\begin{array}{l}\text { AGC with portal vein } \\
\text { tumor thrombosis }\end{array}$ & Cycle 6 & Severe fatigue & $\begin{array}{l}\text { Pretreatment free T3: } 3.29 \mathrm{pg} / \mathrm{mL} \\
\text { Pretreatment free T4: } 1.43 \mathrm{ng} / \mathrm{dL} \\
\text { Pretreatment TSH: } 0.67 \mathrm{mlU} / \mathrm{L} \\
\text { Serum sodium: } 109 \mathrm{mmol} / \mathrm{L} \\
\text { Random urinary sodium: } 64 \mathrm{mmol} / \mathrm{L} \\
\text { Free T3: } 0.39 \mathrm{pg} / \mathrm{mL} \\
\text { Free T4: } 0.15 \mathrm{ng} / \mathrm{dL} \\
\text { TSH: } 136.50 \mathrm{mIU} / \mathrm{L} \\
\text { Antithyroglobulin antibody: } 70.60 \mathrm{U} / \mathrm{mL} \\
\text { Antithyroid peroxidase: } 55.02 \mathrm{U} / \mathrm{mL} \\
\text { Rapid ACTH test }\end{array}$ & $\begin{array}{l}\text { Thyroid ultrasonography: atrophic } \\
\text { changes in both lobes of the thy- } \\
\text { roid gland } \\
\text { Brain MRI: no abnormality in the pi- } \\
\text { tuitary gland }\end{array}$ \\
\hline
\end{tabular}

$\mathrm{M}$, male; AGC, advanced gastric cancer; TSH, thyroid-stimulating hormone; ACTH, adrenocorticotropic hormone; MRI, magnetic resonance imaging. ${ }^{\text {a) }}$ Serum cortisol is $<0.5,2.27,3.56 \mu \mathrm{g} / \mathrm{dL}$ at $0,30,60$ minutes, respectively; serum ACTH is $20.23 \mathrm{pg} / \mathrm{mL}$ at 0 minute.

sufficiency are well controlled with levothyroxine $(0.05 \mathrm{mg})$ per day and hydrocortisone twice daily $(10 \mathrm{mg}$ on awakening and in the early evening).

\section{Discussion}

ICIs are now considered the standard of care for melanoma, NS$\mathrm{CLC}$, and renal cancer. An increasing number of agents are available, and the list of indications is growing, including gastric cancer. Tislelizumab is a humanized IgG4 anti-PD-1 mAb that has been developed for the treatment of hematological malignancies and advanced solid tumors [4]. The low affinity of tislelizumab for Fc $\gamma \mathrm{RI}$ may result in improved anticancer efficacy. ICIs have been shown to cause a unique set of toxicities, irAEs, which are different from those previously reported for cytotoxic agents. ICIs may affect peripheral tolerance to autoantigens, resulting in autoantibody formation, which could be associated with irAEs in various organs. Endocrine AEs are the most common irAEs. The majority of irAEs are mild to moderate and self-limiting, but a few of them, including adrenal insufficiency, can lead to potentially life-threatening events [5].

ICI-related adrenal insufficiency is a rare disease, and a systemat- ic review reported that the incidence of adrenal insufficiency of any grade was $0.7 \%$, and the incidence of grade 3 or higher was only $0.2 \%$ [6]. However, recognition is important because it may be severe or life-threatening. There is no clearly defined time frame for the development of adrenal insufficiency. It can develop in the first month of treatment, but some cases have been reported several years after treatment. In this study, adrenal insufficiency developed after six and 13 cycles of treatment in cases 1 and 2, respectively. The presentation of adrenal insufficiency may vary from asymptomatic laboratory abnormalities to serious medical conditions [7]. Symptoms are also vague and nonspecific; fatigue, dizziness, and anorexia are frequent symptoms, and refractory hypotension and altered state of consciousness may present in severe cases. Hyponatremia and hyperkalemia are frequently reported. Hyponatremia is mediated by increased release of antidiuretic hormone $(\mathrm{ADH})$, which results in water retention and a dilutional decrease in serum sodium levels [8]. The increased secretion of $\mathrm{ADH}$ is caused by cortisol deficiency; hence, cortisol deficiency results in the increased hypothalamic secretion of corticotropin-releasing hormone, an $\mathrm{ADH}$ secretagogue [9]. Increased $\mathrm{ADH}$ secretion is also attributed in part to the reduction in systemic blood pressure and cardiac output. In addition, cortisol directly suppresses $\mathrm{ADH}$ 
secretion [10]. Differential diagnoses may include central (immune-mediated hypophysitis with secondary adrenal insufficiency, hypophyseal metastasis) and peripheral (adrenal metastasis, adrenal hemorrhage) potential causes, while infections, drugs, and infiltrative diseases should also be considered. Laboratory tests and imaging studies, including morning cortisol, ACTH, ACTH-stimulation test, adrenal gland computed tomography, and hypophysis MRI, may be helpful for differential diagnosis. Management should include holding ICIs until a patient is stabilized, hydrocortisone, and fluid resuscitation based on clinical severity. ICIs with appropriate hormone replacement can be continued.

Some studies have suggested an association between irAEs and clinical benefits, but it has not yet been identified $[11,12]$. Hussaini et al. [13] reported a positive association between the development of irAEs and objective response rate (ORR), progression-free survival, and overall survival (OS). They also reported that grade 3 or $4 \mathrm{irAEs}$ were associated with better ORR but worse OS. In our case studies, both patients showed a partial response. One patient achieved a near-complete response, and the response has been sustained for over 11 months. Further studies are required to investigate the association between irAEs and the efficacy of ICIs and to improve the control of irAEs and the clinical practice of ICIs.

This study presented two cases of adrenal insufficiency that developed during tislelizumab therapy in patients with advanced gastric cancer. The guidelines of the American Society of Clinical Oncology recommend testing for TSH and free T4 every 4 to 6 weeks as part of routine clinical monitoring or for case detection in symptomatic patients, but regular monitoring for adrenal insufficiency is not recommended [14]. Therefore, increased awareness of ICI-related adrenal insufficiency is crucial for early detection and prompt management in patients treated with ICIs.

\section{Notes}

\section{Conflicts of interest}

No potential conflict of interest relevant to this article was reported.

\section{ORCID}

Jin Ho Baek, https://orcid.org/0000-0003-2523-9950

\section{References}

1. Global Burden of Disease Cancer Collaboration; Fitzmaurice C, Allen C, Barber RM, Barregard L, Bhutta ZA, et al. Global, regional, and national cancer incidence, mortality, years of life lost, years lived with disability, and disability-adjusted life-years for 32 cancer groups, 1990 to 2015: a systematic analysis for the global burden of disease study. JAMA Oncol 2017;3:52448.

2. Jim MA, Pinheiro PS, Carreira H, Espey DK, Wiggins CL, Weir HK. Stomach cancer survival in the United States by race and stage (2001-2009): findings from the CONCORD-2 study. Cancer 2017;123(Suppl 24):4994-5013.

3. Zhang T, Song X, Xu L, Ma J, Zhang Y, Gong W, et al. The binding of an anti-PD-1 antibody to Fc $\gamma \mathrm{RI}$ has a profound impact on its biological functions. Cancer Immunol Immunother 2018;67:1079-90.

4. Lee A, Keam SJ. Tislelizumab: first approval. Drugs 2020;80: $617-24$.

5. Borghaei H, Paz-Ares L, Horn L, Spigel DR, Steins M, Ready NE, et al. Nivolumab versus docetaxel in advanced nonsquamous non-small-cell lung cancer. N Engl J Med 2015;373: 1627-39.

6. Barroso-Sousa R, Barry WT, Garrido-Castro AC, Hodi FS, Min L, Krop IE, et al. Incidence of endocrine dysfunction following the use of different immune checkpoint inhibitor regimens: a systematic review and meta-analysis. JAMA Oncol 2018; 4:173-82.

7. Wang DY, Salem JE, Cohen JV, Chandra S, Menzer C, Ye F, et al. Fatal toxic effects associated with immune checkpoint inhibitors: a systematic review and meta-analysis. JAMA Oncol 2018;4:1721-8.

8. Oelkers W. Hyponatremia and inappropriate secretion of vasopressin (antidiuretic hormone) in patients with hypopituitarism. N Engl J Med 1989;321:492-6.

9. Wolfson B, Manning RW, Davis LG, Arentzen R, Baldino F Jr. Co-localization of corticotropin releasing factor and vasopressin mRNA in neurones after adrenalectomy. Nature 1985;315:5961.

10. Watts AG, Tanimura S, Sanchez-Watts G. Corticotropin-releasing hormone and arginine vasopressin gene transcription in the hypothalamic paraventricular nucleus of unstressed rats: daily rhythms and their interactions with corticosterone. Endocrinology 2004;145:529-40.

11.Judd J, Zibelman M, HandorfE, O'Neill J, Ramamurthy C, Bentota $\mathrm{S}$, et al. Immune-related adverse events as a biomarker in non-melanoma patients treated with programmed cell death 1 inhibitors. Oncologist 2017;22:1232-7.

12. Horvat TZ, Adel NG, Dang TO, Momtaz P, Postow MA, Callahan MK, et al. Immune-related adverse events, need for systemic immunosuppression, and effects on survival and time to treatment failure in patients with melanoma treated with ipilim- 
umab at Memorial Sloan Kettering Cancer Center. J Clin Oncol 2015;33:3193-8.

13. Hussaini S, Chehade R, Boldt RG, Raphael J, Blanchette P, Maleki Vareki S, et al. Association between immune-related side effects and efficacy and benefit of immune checkpoint inhibitors: a systematic review and meta-analysis. Cancer Treat Rev
2021;92:102134.

14. Brahmer JR, Lacchetti C, Schneider BJ, Atkins MB, Brassil KJ, Caterino JM, et al. Management of immune-related adverse events in patients treated with immune checkpoint inhibitor therapy: American Society of Clinical Oncology clinical practice guideline.J Clin Oncol 2018;36:1714-68. 